\title{
Correlated changes in behavioral indicators of lameness in dairy cows following hoof trimming
}

\author{
N. Chapinal, ${ }^{\star 1}$ A. M. de Passillé, $†$ and J. Rushen† \\ *Animal Welfare Program, University of British Columbia, Vancouver, Canada V6T $1 Z 4$ \\ †Agriculture and Agri-Food Canada, Agassiz, BC, Canada V0M 1A0
}

\begin{abstract}
Cow gait, walking speed, time spent lying down, and distribution of weight among legs when standing during the week before and up to $5 \mathrm{wk}$ after hoof trimming were assessed in 48 lactating Holstein cows housed in freestall pens to examine how changes in gait score following hoof trimming were correlated with other behavioral changes. Gait responses to hoof trimming varied between cows, with the majority showing no change or an increase in gait score. Walking speed was reduced after hoof trimming, and this decrease was maintained during the following $4 \mathrm{wk}$. The change in walking speed following hoof trimming negatively correlated with the change in gait $(\mathrm{r}=-0.33)$. Before hoof trimming, lame cows showed a greater standard deviation of the weight applied to the rear legs (38.4 vs. 27.2; standard error of the difference $=4.6$ ). After hoof trimming, lame cows showed a quadratic increase in the standard deviation of the weight applied to the rear legs and the rear leg weight ratio, whereas no time trend existed for nonlame cows. The change in gait following hoof trimming was negatively correlated with the change in leg weight ratio $(\mathrm{r}=-0.44)$. Before hoof trimming, lame cows spent more time lying down each day than nonlame cows (801.7 vs. $731.7 \mathrm{~min} / \mathrm{d}$; standard error of the difference $=29.7)$. Both lame and nonlame cows increased the time they spent each day lying down after hoof trimming, and daily lying time remained higher for up to $5 \mathrm{wk}$ after hoof trimming. The change in time spent lying down after hoof trimming was correlated with the change in gait $(\mathrm{r}=0.30)$ and the change in leg weight ratio $(\mathrm{r}=-0.47)$. Using automated methods of lameness detection shows promise as a way of continuously monitoring animals to detect changes in behavior associated with the onset of or recovery from lameness.
\end{abstract}

Key words: activity, gait, lameness, weight distribution

Received May 11, 2010.

Accepted September 1, 2010.

${ }^{1}$ Corresponding author: nchapinal@yahoo.com

\section{INTRODUCTION}

Despite the importance of lameness in dairy cattle, producers have difficulty detecting lame cows (Whay et al., 2003), which demonstrates the need for better detection methods. Traditionally, lame cows have been detected by gait scoring, but the increasing size of farms has led to interest in automated methods of lameness detection. Lameness in cows is associated with several behavioral changes that could be monitored automatically, such as an uneven distribution of weight among the legs or greater shifting of weight among legs when cows are standing, increased time spent lying down, or reduced walking speed (O'Callaghan et al., 2003; Pastell and Kujala, 2007; Chapinal et al., 2009b, 2010; Pastell et al., 2010). The extent to which these behavioral changes could be used to monitor lameness or responses to treatment has not been examined. Furthermore, the causal relationship between these other behaviors and impaired gait is not fully understood. For example, is an uneven weight distribution among the legs (Chapinal et al., 2010; Pastell et al., 2010) a result of lameness or a predisposing cause of lameness? Lameness is associated with both an increase and a decrease in time spent lying down (Cook et al., 2004; Chapinal et al., 2009b; Ito et al., 2009a), but some results (Chapinal et al., 2009b; Proudfoot et al., 2010) suggest that the relationship between lameness and time spent lying down may change over time with the development of hoof lesions preceded by reduced time spent lying down and subsequently followed by increased time spent lying down.

To evaluate the use of automatically monitoring behavioral changes to track deterioration in gait or recovery from lameness, and to understand the causal relationships between impaired gait and the other behavioral changes with which it is associated, gait had to be experimentally altered and the correlated changes with other behaviors examined.

The objective was to examine the correlation between changes in gait following hoof trimming and changes in measures of weight distribution and activity. Hoof trimming was used as a way to induce a change in gait as regular hoof trimming has led to improved hoof health (Manske et al., 2002a) and improved locomotion 
(Phillips et al., 2000). The hypothesis was that gait scores would be lower following hoof trimming, and that reduced gait scores would be associated with a reduction in time spent lying down, an increase in walking speed, increased symmetry in weight applied to the rear legs, and reduced weight shifting between the rear legs, when the cows were standing.

\section{MATERIALS AND METHODS}

\section{Animals and Housing}

Forty-eight lactating Holstein cows (mean $\pm \mathrm{SD}$; parity $=2.7 \pm 1.9 ; \mathrm{BW}=668 \pm 83 \mathrm{~kg} ; \mathrm{DIM}=214 \pm 59$ $\mathrm{d}$; 305-d milk production $=11,709 \pm 2,058 \mathrm{~kg}$ ) were used from the herd at the University of British Columbia's Dairy Education and Research Centre. Cows were housed in sand-bedded freestalls $(2.4 \mathrm{~m}$ long $\times 1.18 \mathrm{~m}$ wide $\times 0.40 \mathrm{~m}$ deep) in groups of 12 cows per pen with 1 lying stall per cow. Cows were fed a TMR diet available ad libitum with fresh feed delivered twice daily at 0700 and $1600 \mathrm{~h}$, formulated to meet requirements for lactating dairy cows (NRC, 2001). Water was freely available from self-filling troughs. Lactating cows were milked twice daily in the parlor at approximately 0800 and $1700 \mathrm{~h}$.

\section{Experimental Procedure}

The experimental protocol was approved by the Institutional Animal Care Committee, which is monitored by the Canadian Council on Animal Care. Cows had their hooves trimmed by a professional hoof trimmer using the normal procedures employed by that trimmer during routine hoof trimming. An experienced observer examined the front and rear hooves and recorded the presence, location, and severity of sole hemorrhages and sole ulcers following the 1-to- 8 score described by Leach et al. (1998), and digital dermatitis following the 1-to-5 score described by Manske et al. (2002b).

Cows were fitted with activity loggers (Tinytag Plus, Gemini Dataloggers, Ltd., Chichester, UK) 5 d before hoof trimming to measure time spent standing and lying (O'Driscoll et al., 2008). The activity logger was placed in a fabric pouch and attached to one of the rear legs of each cow using Vet-Wrap (CoFolex, Andover Coated Products, Inc., Salisbury, MA). The activity loggers were programmed to record the position of the cow (lying or standing) once per min. Lying behavior data were collected for 4 to 6 consecutive days during wk $-1,1,3$, and 5 relative to hoof trimming (d 0). Gait, walking speed, and weight distribution were measured on $\mathrm{d}-4,-1,1,2,3,8,15,22$, and 29 relative to hoof trimming using the methods described below.

\section{Data Collection}

Gait Score. Cows had their gait scored while walking down a familiar $13 \times 1.3 \mathrm{~m}$ ungrooved concrete passageway. A handler walked behind the cows, encouraging them to walk in a consistent manner. Cows were familiarized with the area and the procedure by repeatedly walking down the passageway 4 times/d for at least $4 \mathrm{~d}$ before they were scored. Cows were walked at least 4 times on the days of data collection. Cows were videotaped at normal speed from the right side with a color digital camera (30 frames/s; DCRSR100 HDD Handycam, Sony Corp., Park Ridge, NJ) placed $8 \mathrm{~m}$ from the cow, which allowed recording at least 4 complete strides for each cow during each passage. Two trained and experienced observers watched the videos and assigned a gait score to each cow for each day by using a 1-to-5 numerical rating system (NRS; where $1=$ perfect gait and $5=$ severely lame) based on the several specific gait attributes as described by Flower and Weary (2006) and Chapinal et al. (2009b). If a cow exceeded the requirements of a particular score, a half-integer score was allocated. Overall gait was also assessed on a continuous 100-unit visual analog scale (VAS; Flower and Weary, 2006). Before hoof trimming, both observers scored the gait of all the cows on $\mathrm{d}-4$ and -1 to assess which cows were lame. After hoof trimming, each observer scored the gait of half of the cows for the passages recorded. To calculate interobserver reliability, 24 randomly selected passages were scored by both observers for NRS and overall VAS ( $\mathrm{r}=$ 0.88 and 0.78 respectively, $P<0.001$ ).

Walking Speed. Two marks separated by $9.35 \mathrm{~m}$ were painted on the floor and walls of the same passageway used for scoring gait. Using the same video recordings as for scoring gait, the time between when the nose of the cow was aligned with the starting and end mark was measured using specialized software (The Observer, v. 5, Noldus Information Technology, Wageningen, the Netherlands). Mean walking speed during each passage was then calculated from these data.

Weighing Platform. The distribution of weight among the legs was measured while cows were standing on a platform (described in Chapinal et al., 2009a; Pastell et al., 2010) at the end of the passageway where they were walked. Cows were familiarized with the platform and the procedure by standing on the platform 4 times/d for at least $4 \mathrm{~d}$ before data were collected. The platform had 4 independent recording units (each $56 \times$ $91 \mathrm{~cm})$ fitted in a $1.9 \times 1.3 \mathrm{~m}$ enclosure. The weight placed on each leg was recorded at a rate of 6 readings/s. Cows stood on the platform twice for 3 min on each day of data collection. Due to technical problems, only data from the first 24 cows were collected. 


\section{Statistical Analysis}

All statistical analyses were performed with SAS (v. 9.1, Cary, NC; SAS Institute, 2003) using the cow as the experimental unit.

Lameness status was determined according to the mean NRS of each cow on $\mathrm{d}-4$ and -1 before hoof trimming. Cows were classified as lame if the initial NRS was $>3$, as suggested by Flower and Weary (2006) and Chapinal et al. (2009b). Eleven cows out of 48 were classified as lame (average NRS range $=3.25$, 4.5 ). Four of the lame cows had a sole ulcer (score $\geq 6$ ), 4 cows had moderate to severe sole hemorrhages (score $\geq 3$ ), and 1 had mild digital dermatitis ( Two lame cows had no obvious hoof lesions. Of the 37 cows classified as nonlame (NRS $\leq 3), 6$ cows had a sole ulcer, 12 cows had sole hemorrhage, and 2 had mild digital dermatitis.

Data from the activity loggers were used to quantify the total time spent lying down per day (O'Driscoll et al., 2008). Readings from the weighing platform in which the total weight recorded was $5 \%$ above or below the mode of the total weight within the passage were discarded as described in Chapinal et al. (2009a). Readings from each passage were summarized to get the mean weight applied on each leg. Data for the rear pair of legs were averaged by day and animal for the analysis. Two variables that were shown in the literature to be indicators of lameness were calculated. These were (1) the SD of the weight applied to each leg over the 5 -min period as a measure of leg-load variability or weight shifting between legs over time (Rushen et al., 2007), and (2) the leg weight ratio (LWR) between the lighter and the heavier leg of the rear pair of legs, as a measure of asymmetry of weight applied to the rear legs (Pastell and Kujala, 2007).

A mixed model (PROC MIXED) that included cow and group as random effects; parity, observer, and lameness status as fixed effects; the linear and quadratic effect of day relative to hoof trimming as repeated measures; and the pairwise interactions between lameness status and the linear and quadratic effect of day was used to test differences in overall VAS and walking speed in response to hoof trimming. Days -4 and -1 were averaged to get a baseline value and a correction was applied in the model (WEIGHT statement). A similar mixed model (that did not include the observer) was used to test differences in the SD applied to the rear pair of legs, the rear LWR, and lying behavior in response to hoof trimming. Daily lying time was averaged by week, and week was considered as the repeated measure instead of day. The autocorrelation structure for each model was chosen according to the lower Bayesian information criterion. Where a significant interaction between lameness status and time was found $(P<0.05)$, the time trend was tested separately for lame and nonlame cows. The same models were used with time as a categorical variable and differences between lame and nonlame cows before hoof trimming were tested by using contrast statements, as well as differences between before and immediately after hoof trimming in the cases when the linear and quadratic effect of time were not significant. Residuals were examined to verify normality and homogeneity of variances after each model.

The change in each variable was measured following hoof trimming by calculating the difference between the mean value on the week before trimming and the mean value on the week following hoof trimming. To correlate changes in NRS and overall VAS to changes in the weight distribution and changes in activity measures and changes in weight distribution measures to changes in activity measures, PROC CORR was used.

\section{RESULTS}

\section{Gait Score}

Two cows had a lower NRS (by 0.5 points or more) after hoof trimming than before, 20 cows had a higher NRS (by 0.5 points or more) after hoof trimming than before, and 26 cows showed no change in NRS (change lower than 0.5 points) after hoof trimming. No linear or quadratic effect of day on VAS was observed (Figure $1 \mathrm{~A} ; P>0.20)$, yet VAS was lower before hoof trimming than the $2 \mathrm{~d}$ following hoof trimming $(P=0.04$ and $P$ $=0.002$, contrast between baseline value and $\mathrm{d} 1$ and $\mathrm{d}$ 2 , respectively). The NRS (Figure 1B) and overall VAS were correlated $(\mathrm{r}=0.94 ; P<0.001)$; therefore, results were very similar for both variables.

\section{Walking Speed}

Before hoof trimming, no differences were found between lame and nonlame cows in walking speed (Figure $1 \mathrm{C} ; P=0.69$ ). Immediately after hoof trimming, a reduction in walking speed was observed in both lame and nonlame cows, and this decrease was maintained during the following weeks $(P=0.04$ for the quadratic effect of time). The change in walking speed following hoof trimming was significantly and negatively correlated with the change in NRS and overall VAS (Table 1). That is, an increase in NRS and overall VAS (i.e., deterioration in gait) was associated with a decrease in walking speed.

\section{Weight Distribution}

Before hoof trimming, lame cows showed a higher $\mathrm{SD}$ of the weight applied to the rear legs compared 
with nonlame cows [38.4 vs. $27.2 \mathrm{~kg}$; standard error of the difference $($ SED $)=4.6 ; P=0.01$; Figure 2A] . The mixed model showed an interaction between the quadratic effect of time and lameness status $(P=0.04)$. After hoof trimming, lame cows showed a quadratic increase in the SD of the weight applied to the rear legs $(P=0.03)$, whereas no time trend was found for nonlame cows $(P>0.2)$.

Before hoof trimming, lame cows tended to show a lower rear LWR $(0.71$ vs. 0.81 SED $=0.05 ; P=$ 0.06 ; Figure 2B) than nonlame cows. The mixed model showed an interaction between the quadratic effect of time and lameness status $(P=0.001)$. After hoof trimming, lame cows showed a quadratic increase in the rear LWR $(P=0.04)$, whereas no time trend was found in the case of nonlame cows $(P>0.2)$.

The change in NRS following hoof trimming was negatively correlated with the change in LWR (Table 1 ), but not with the change in the SD of the weight
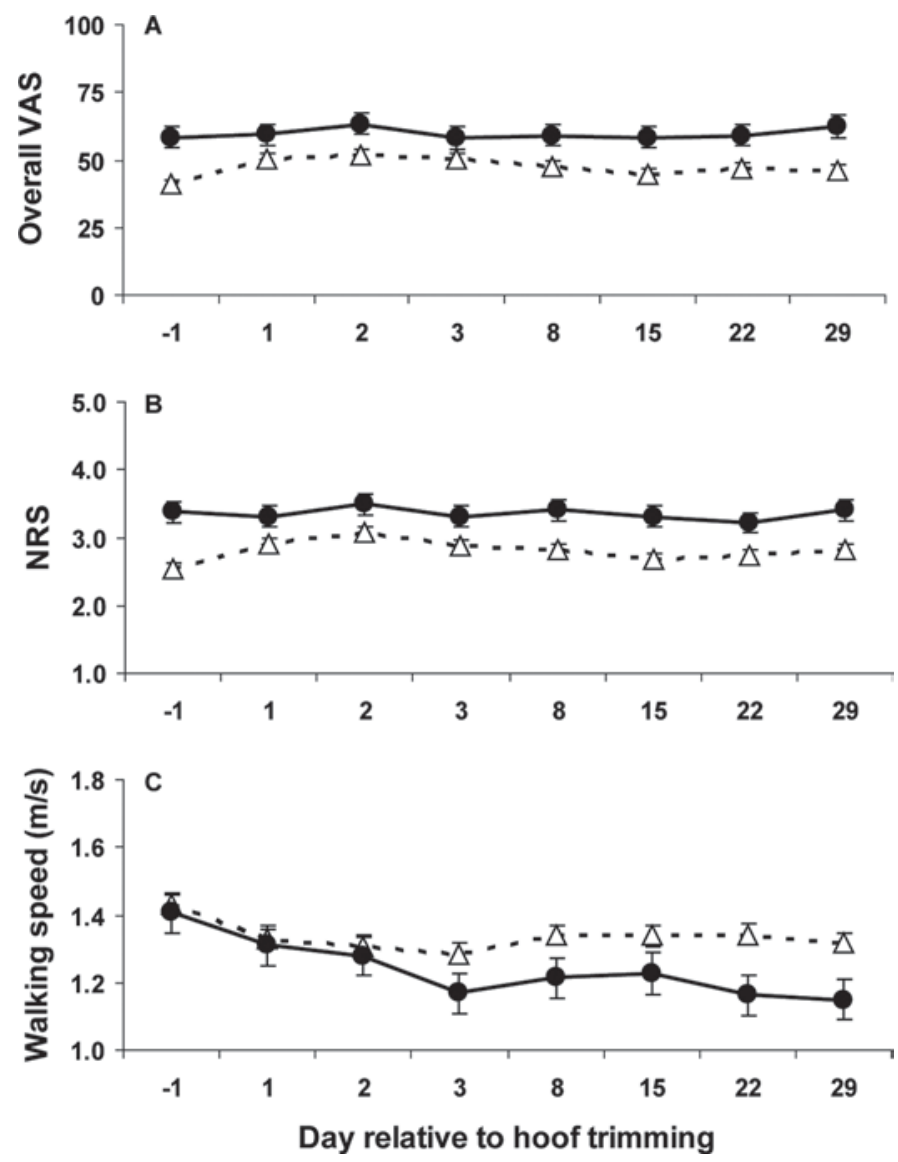

Figure 1. Mean $\pm \mathrm{SE}$ of gait scores (A, B) and walking speed (C) over $29 \mathrm{~d}$ after hoof trimming for 11 lame (initial numerical rating system score $>3$, black circle) and 37 nonlame (white triangle) Holstein cows housed in freestall pens. Day -1 is an average of $d-4$ and -1 . $\mathrm{NRS}=$ numerical rating system; VAS $=$ continuous 100 -unit visual analog scale.
Table 1. Correlation between changes from the week before to the week after hoof trimming in gait scores (numerical rating system or overall visual analog scale) and walking speed, rear leg weight ratio (LWR), and time spent lying down for 48 Holstein cows housed in freestall pens ${ }^{1}$

\begin{tabular}{lccc}
\hline Item & NRS & VAS & LWR \\
\hline Walking speed & $-0.33^{*}$ & $-0.33^{*}$ & 0.16 \\
LWR & $-0.44^{*}$ & $-0.38 \dagger$ & $\mathrm{NA}^{2}$ \\
Lying time/day & $0.30^{*}$ & $0.28 \dagger$ & $-0.47^{*}$ \\
\hline
\end{tabular}

${ }^{1}$ Measures of weight distribution were collected for 24 of the cows. NRS = numerical rating system; VAS = continuous 100 -unit visual analog scale.

${ }^{2}$ Not applicable.

$* P<0.05 ; \dagger P<0.10$.

applied to the rear legs $(P>0.10)$. That is, an increase in NRS (i.e., deterioration in gait) was associated with an increased asymmetry of weight applied to the rear legs.

\section{Time Spent Lying Down}

Before hoof trimming, lame cows spent more time lying down per day than nonlame cows (801.7 vs. 731.7 $\min / \mathrm{d} ; \mathrm{SED}=29.7 ; P=0.02 ;$ Figure 3$)$. Both lame and nonlame cows increased the time they spent lying down each day after hoof trimming, and daily lying time remained higher for up to 5 wk after hoof trim-

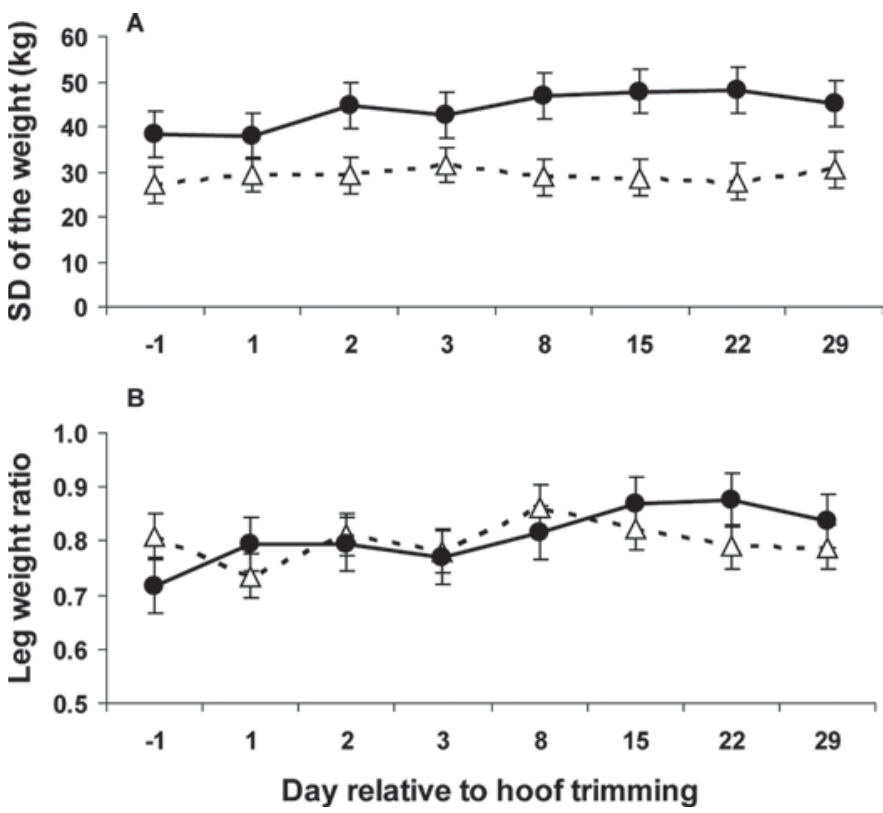

Figure 2. Mean $\pm \mathrm{SE}$ of the SD over time of the weight applied to the rear legs (A) and the rear leg weight ratio (LWR; B) over $29 \mathrm{~d}$ after hoof trimming for 8 lame (initial numerical rating system score $>3$, black circle) and 16 nonlame (white triangle) Holstein cows housed in freestall pens. Day -1 is an average of $d-4$ and -1 . 


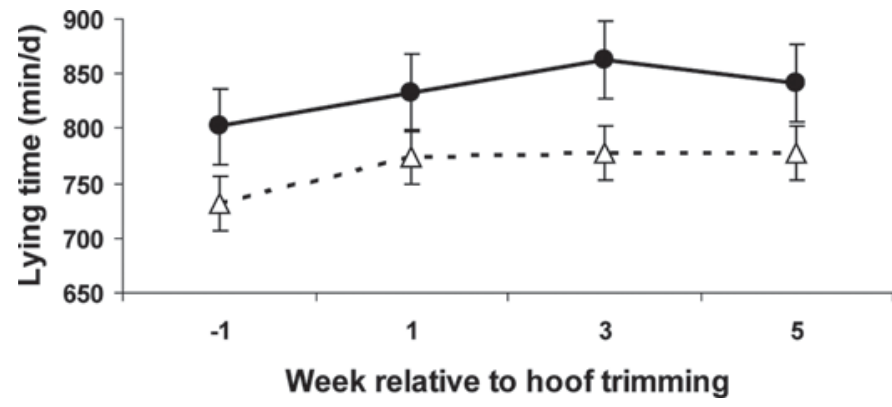

Figure 3. Mean $\pm \mathrm{SE}$ of the daily lying time over 5 wk after hoof trimming for 11 lame (initial numerical rating system score $>3$, black circle) and 37 nonlame (white triangle) Holstein cows housed in freestall pens.

ming $(P<0.001$ for the quadratic effect of week). The change in time spent lying down after hoof trimming was positively correlated with the change in NRS (Table 1). That is, an increase in NRS (i.e., deterioration in gait) was associated with an increase in the amount of time spent lying down each day. A positive correlation was found between the change in time spent lying down and the change in LWR.

\section{DISCUSSION}

Prior to hoof trimming, lame cows (classified based on gait scores) distributed their weight unevenly between their rear legs when standing (shown by the LWR), showed more weight shifting between their rear legs when standing (shown by the SD of weight applied to the rear legs), and spent more time lying down than nonlame cows. This supports previous findings (Rushen et al., 2007; Chapinal et al., 2009b; Pastell et al., 2010), as well as the suggestion that these behavioral measures can help to identify lame cows. No differences in walking speed were found, however, which conflicts with previous findings (Chapinal et al., 2009b, 2010).

To our knowledge, this is the first study to correlate changes in gait scores with changes in the behaviors associated with lameness rather than reporting a simple association found during a single time point. Continuous monitoring of behavior on farm could help producers and veterinarians to identify cows becoming lame and monitor the recovery following treatment for lameness, particularly in large herds. Continuous monitoring of behavior is only feasible by automated methods, such as weighing scales installed in an automated milking system (Pastell and Kujala, 2007) or activity loggers (Ito et al., 2009b). A combination of different automated methods of lameness detection can increase the likelihood of detecting lame cows (Chapinal et al., 2010).
Changes following hoof trimming in the time that the cows spent lying down were more correlated with changes in the asymmetry of weight distribution (LWR) than they were with changes in gait scores. This suggests that changes in how cattle distribute their weight between their legs may be a more sensitive measure of lameness or problems with hoof shape than are gait scores. This supports previous findings that measures of weight distribution are more sensitive to the effects of analgesics and local anesthetics than are gait scores (Rushen et al., 2007; Chapinal et al., 2010). Although altered gait is the most visible consequence of hoof lesions or hoof problems, this may not be the best measure to detect hoof problems.

Cows had hooves trimmed to induce a change in gait score and study how other lameness predictors changed simultaneously. Based on previous literature, which showed a beneficial effect of hoof trimming on lameness (Manske et al., 2002a; Somers et al., 2005), hoof trimming was expected to improve gait. Contrary to these expectations, most cows showed either no change or a deterioration in gait. Little research has been done on the immediate effect of hoof trimming in gait scoring (Phillips et al., 2000; van der Tol et al., 2004). It was not our aim to assess the effect of hoof trimming, and only 1 hoof trimmer was involved during routine hoof trimming. Nevertheless, concern has been raised about the efficiency of hoof-trimming techniques (van der Tol et al., 2004; Nuss and Paulus, 2006), and further research is needed to assess their effectiveness.

In conclusion, using automated methods of lameness detection shows promise as a way of continuously monitoring animals to detect changes in behavior associated with either the onset of lameness or responses to treatment.

\section{ACKNOWLEDGMENTS}

We thank Gosia Zdanowicz, Mairi Robertson, and the staff and students at the University of British Columbia's Dairy Education and Research Centre (Agassiz, BC, Canada). The research was supported by the Natural Sciences and Engineering Research Council of Canada, Dairy Farmers of Canada, and Agriculture and Agri-Food Canada.

\section{REFERENCES}

Chapinal, N., A. M. de Passillé, and J. Rushen. 2009a. Weight distribution and gait in dairy cattle are affected by milking and late pregnancy. J. Dairy Sci. 92:581-588.

Chapinal, N., A. M. de Passillé, J. Rushen, and S. Wagner. 2010. Automated methods for the detection of lameness and analgesia in dairy cattle. J. Dairy Sci. 93:2007-2013. 
Chapinal, N., A. M. de Passillé, D. M. Weary, M. A. G. von Keyserlingk, and J. Rushen. 2009b. Using gait score, walking speed, and lying behavior to detect hoof lesions in dairy cows. J. Dairy Sci. 92:4365-4374.

Cook, N. B., T. B. Bennett, and K. V. Nordlund. 2004. Effect of free stall surface on daily activity patterns in dairy cows with relevance to lameness prevalence. J. Dairy Sci. 87:2912-2922.

Flower, F. C., and D. M. Weary. 2006. Effect of hoof pathologies on subjective assessments of dairy cow gait. J. Dairy Sci. 89:139 146.

Ito, K., D. M. Weary, and M. A. G. von Keyserlingk. 2009a. Extreme lying times predict lameness. Proc. 9th ISAE N. Am. Regional Mtg., Montreal, Canada.

Ito, K., D. M. Weary, and M. A. G. von Keyserlingk. 2009b. Lying behavior: Assessing within- and between-herd variation in freestall-housed dairy cows. J. Dairy Sci. 92:4412-4420.

Leach, K. A., D. N. Logue, J. M. Randall, and S. A. Kempson. 1998. Claw lesions in dairy cattle: Methods for assessment of sole and white line lesions. Vet. J. 155:91-102.

Manske, T., J. Hultgren, and C. Bergsten. 2002a. The effect of claw trimming on the hoof health of Swedish dairy cattle. Prev. Vet. Med. 54:113-129.

Manske, T., J. Hultgren, and C. Bergsten. 2002b. Topical treatment of digital dermatitis associated with severe heel-horn erosion in a Swedish dairy herd. Prev. Vet. Med. 53:215-231.

NRC. 2001. Nutrient Requirement of Dairy Cattle. 7th rev. ed. National Academy Press, Washington, DC.

Nuss, K., and N. Paulus. 2006. Measurements of claw dimensions in cows before and after functional trimming: A post-mortem study. Vet. J. 172:284-292.

O'Callaghan, K. A., P. J. Cripps, D. Y. Downham, and R. D. Murray. 2003. Subjective and objective assessment of pain and discomfort due to lameness in dairy cattle. Anim. Welf. 12:605-610.
O'Driscoll, K., L. Boyle, and A. Hanlon. 2008. A brief note on the validation of a system for recording lying behaviour in dairy cows. Appl. Anim. Behav. Sci. 111:195-200.

Pastell, M., L. Hänninen, A. M. de Passillé, and J. Rushen. 2010. Measures of weight distribution of dairy cows to detect lameness and the presence of hoof lesions. J. Dairy Sci. 93:954-960.

Pastell, M. E., and M. Kujala. 2007. A probabilistic neural network model for lameness detection. J. Dairy Sci. 90:2283-2292.

Phillips, C. J., P. C. Chiy, M. J. Bucktrout, S. M. Collins, C. J. Gasson, A. C. Jenkins, and M. J. Paranhos da Costa. 2000. Frictional properties of cattle hooves and their conformation after trimming. Vet. Rec. 146:607-609.

Proudfoot, K. L., D. M. Weary, and M. A. G. von Keyserlingk. 2010 Behavior during transition differs for cows diagnosed with claw horn lesions in mid lactation. J. Dairy Sci. 93:3970-3978.

Rushen, J., E. Pombourcq, and A. M. de Passillé. 2007. Validation of two measures of lameness in dairy cows. Appl. Anim. Behav. Sci 106:173-177.

SAS Institute. 2003. SAS User's Guide. SAS Institute Inc., Cary, NC.

Somers, J. G. C. J., K. Frankena, E. N. Noordhuizen-Stassen, and J. H. M. Metz. 2005. Risk factors for interdigital dermatitis and heel erosion in dairy cows kept in cubicle housing in The Netherlands. Prev. Vet. Med. 71:23-34.

van der Tol, P. P., S. S. van der Beek, J. H. Metz, E. N. NoordhuizenStassen, W. Back, C. R. Braam, and W. A. Weijs. 2004. The effect of preventive trimming on weight bearing and force balance on the claws of dairy cattle. J. Dairy Sci. 87:1732-1738.

Whay, H. R., D. C. Main, L. E. Green, and A. J. Webster. 2003. Assessment of the welfare of dairy cattle using animal-based measurements: Direct observations and investigation of farm records. Vet. Rec. 153:197-202. 